\title{
La construcción del pensamiento femenino en una sociedad agraria durante el franquismo: Istán (Málaga)
}

\author{
Rosa María Badillo Baena
}

"Conocerse es poseerse. Sabedora de si misma, la sociedad será dueña de sí misma».

Jaime Vera

\section{DEFINICIÓN DEL OBJETO DE INVESTIGACIÓN}

Este trabajo es una aproximación al estudio de los procesos de construcción del pensamiento, a través del análisis de una sociedad agraria concreta: Istán. En ella se detectan con claridad meridiana las transformaciones, las rupturas, debido a las grandes contradicciones entre ideologías y universos simbólicos opuestos: Formas precapitalistas/ Formas capitalistas. Campo aislado-economia autárquica/Campo apéndice de lo urbano-economía dependiente de la ciudad. Socialización familiar/Socialización escolar.

Istán se caracteriza por ser un pueblo de la Serranía, donde el medio ha determinado acentuadamente su economía y la distribución social del conocimiento. Hasta el punto de que el poder no es sinónimo de tenencia de tierras, sino que el poder es "saber". En esta comunidad existe un gran espíritu colectivo, con un sedimento de tradiciones, fiestas y creencias, que han cohesionado a sus miembros fuertemente. Los hechos se viven como experiencia colectiva, y la distorsión de estos hechos supone 
una explosión, una huella indeleble en la memoria. En Istán las instituciones son una persona. Este es el caso de una maestra, de nombre: Francisca Ruíz Ponce, que selló la mente individual y la conciencia colectiva de sus gentes durante cuarenta años.

El tiempo histórico que vertebra la trama de los sucesos aquí narrados, se corresponde con el Franquismo. Constructor de un universo simbólico que se impone a distintas formas de cultura, colonizándolas. En Istán, se dio un fuerte grado de asimilación de la moral y la ideología fabricadas por los vencedores de la contienda civil. "Se borra el rastro de los vencidos", incluso dejarán de ser nombrados en sus casas, en los lugares que habitaron. Borrados del lenguaje, eliminados de la realidad, casi desaparecieron en la memoria colectiva de las nuevas generaciones, a las que se les construyó un pasado a medida del Régimen Franquista. Operación realizada desde la escuela.

A este nuevo rumbo ideológico y político, se suman en Istán, otros cambios, los económicos. El pueblo progresivamente se convertirá en un apéndice del núcleo urbano de Marbella. El espiritu capitalista se va introduciendo en el seno de la comunidad, con la dedicación de la problación a las actividades turísticas de la Costa. Nuevos horarios, otras formas de vida - producto del cambio radical de trabajo-, y el fenómeno de la emigración, transgreden y roban terreno al universo simbólico agrario cuya pervivencia se desvirtúa a un ritmo acelerado.

Este esquema adquiere una mayor complejidad y riqueza, cuando se observa la función de los géneros en el seno de esta dinámica cultural. Precisamente, el objetivo de este estudio es la formación de pensamiento femenino, la construcción y asimilación de roles a través de la trasmisión oral. Cuestión estrechamente relacionada con los procesos de socialización del género femenino, centrados en la familia y la escuela. Curiosamente en Istán se da un mayor nivel de instrucción en las mujeres, debido a una serie de circunstancias que han hecho posible que este pueblo disfrute de una Alcaldesa y una erudita local. Todos estos factores han despertado mi interés por el presente y pasado de este pueblo.

\section{FUENTES Y MÉTODO. LA ENTREVISTA COLECTIVA}

La fuente oral es la base de esta investigación donde los propios protagonistas de la historia toman la palabra ${ }^{\dagger}$. Para realizar este trabajo

' Han sido entrevistadas veinticinco mujeres con edades comprendidas entre veinti- 
se ha utilizado prioritariamente "la entrevista colectiva" cuyas ventajas pone de manifiesto Jesús Ibáñez en Mas allá de la Sociología ${ }^{2}$. Su uso está motivado por razones epistemológicas y de indole metodológica. Concretamente al historiador le aporta una mayor riqueza de mensajes para interpretar el pasado. Pero hay más motivos, si partimos del enfoque de la encuesta junto con el examen y la confesión como tecnologías, utilizadas por el poder, como "procedimientos de producción de verdad". En algunas fases de la entrevista se identifican los tres procesos, marcados por la selección, la discriminación, la disciplina, la vigilancia y la relación de poder que se establece entre el que pregunta - quién persigue una verdad, dirigiendo el discurso- y el que responde. Este último es un sujeto aislado, separado de la colectividad, seleccionado para ser interrogado. Con el fin de no caer en el error de "la confesión", de la «entrevista en profundidad» utilizando "la encuesta que selecciona a los que pueden ser examinados, y después de muchos exámenes el individuo puede confesarse para el poders ${ }^{3}$. Hemos recurrido al grupo de discusión, a la entrevista colectiva que permita fundir los sujetos, "anular el "yo" para acudir al "nosotros"”.

En este caso, en torno al historiador se han reunido varios grupos de mujeres con una historia común, pero de distintas clases sociales, de distintas ideologias. Esto enriquece la entrevista, porque se recurre al silencio, al disimulo de las diferencias o por el contrario al enfrentamiento directo, cosas que el historiador debe registrar convenientemente. La entrevista colectiva tiene el valor de confrontar los testimonios, de que los propios entrevistados provoquen la memoria, se inciten a recordar y sobre todo a verificar lo que se dice. Según Jesús Ibáñez: «El grupo de discusión -entrevista colectiva - enriquece el repertorio de las técnicas de investigación social en extensión y en profundidad, pues es el único instrumento válido para estudiar las ideologías (en interacción dialéctica con el análisis de textos, relación abierta texto/discurso)... El grupo es la ficción de otro lugar en el que se han abolido las dicotomías bien/mal, verdad/error: el lugar de la madre que está en el origen del saber» ${ }^{4}$.

La entrevista colectiva anula en cierto modo las relaciones de poder que se crean entre entrevistador y entrevistado. El entrevistador juega

cinco y sesenta y cinco años. Constituian varias generaciones, que tenian en común habitar en Istán, participar de la misma cultura, y haber pasado por la escuela, siendo la misma maestra quien les impartió clase: Francisca Ruiz Ponce.

2 IBANNEZ, J., Más allá de la Sociologia. Madrid, Siglo XXI, 1979.

${ }^{3}$ Ibidem, (nota 2).

${ }^{4}$ Ibidem. 
con la ventaja de poseer una cultura científica que le permite disponer de un amplio código lingüístico, cristalizado en un pensamiento reflexivo, mediante el que domina al entrevistado. En cambio, este último, suele estar inserto dentro de una cultura narrativa, utiliza un código lingüístico restringido, su pensamiento es casual. Esto hace factible que el entrevistador imponga sus cuestiones al entrevistado y sólo le permita decir lo que quiere oír. Relación de poder fracturada o suavizada al emplear la técnica del grupo de discusión, donde se dejan fluir los discursos y expresar las actitudes ${ }^{5}$. Incluso el propio concepto de biografía -entendiendo el término como uun todo meditado en el que las acciones discontinuas se piensan, no como hechos aislados sino como partes conexas de un universo subjetivamente significativo cuyos significados se comparten socialmente" ${ }^{6}$ - , sustenta la validez de la entrevista colectiva. Ésta es una de las técnicas más idóneas para estudiar una coletividad, porque los hábitos de comportamiento colectivo se expresan a través del grupo.

En nuestro caso nos ha sido muy útil ya que nos ha servido para establecer el nivel de socialización escolar del colectivo de mujeres estudiado. La huella imprimida por la maestra en el pensamiento de sus alumnas fue muy profunda. Esto queda demostrado -entre otras cosas-, cuando las distintas generaciones de mujeres cantaron a coro las canciones, que varias décadas atrás les había enseñado en el colegio. Mujeres que estaban predispuestas a recuperar la memoria de su maestra, justificando y comprendiendo la dureza de su disciplina con objeto de crearle a ella y crearse colectivamente un hermoso pasado, dando por olvidado los malos momentos, que afloraban alguna vez en los discursos, provocando un gran silencio.

Estas mujeres tenian una fuerte conciencia colectiva de: «haberse perdido mucha inteligencia en el pueblo por el aislamiento". La expresión anterior viene a significar la imposibilidad de seguir estudios superiores. A la pregunta de qué inteligencias se perdieron, fueron señaladas aquellas mujeres que anteriormente, fueron indicadas como las personas con más memoria de la colectividad, "las guardianas del pozo del recuerdo»

${ }^{5}$ La relación de poder que se establece entre individuos que emplean códigos lingüisticos restringido y elaborado respectivamente, es analizada por BERSTEIN, B., "Clases sociales, lenguaje y socialización", en TORREGrosA, J. R., Teoría e investigación social. Madrid, Instituto de Opinión Pública, 1974.

La oposición entre Pensamiento casual/Pensamiento reflexivo es estudiada por RADILLO Baena, Rosa M. ${ }^{a}$. Feminismo y Educación en Málaga: el pensamiento de Suceso Luengo de la Figuera (1898-1920). Málaga, tesina mecanografiada, 1988.

${ }^{6}$ Ibidem, (nota 1). 
en Istán. Esto demuestra que la inteligencia no se había perdido, sino que había sido canalizada según las normas de la cultura narrativa ${ }^{7}$. Estas mujeres, enormemente respetadas, cumplian una función muy importante en la comunidad, eran las relatoras, las guardianas del pasado colectivo.

La entrevista colectiva nos sirvió, también, para establecer el perfil de los individuos, su dominio dentro del grupo. Es interesante constatar la existencia de líderes que cuando tomaban la palabra, todo el mundo callaba. En un momento dado llegaron a dirigir la entrevista, a marcar las interrogaciones, y hasta indicar lo que debia decir el colectivo. Esta es una prueba más de que la inteligencia, aún no siendo encauzada por un saber institucionalizado, es desarrollada y canalizada de otra forma: «no se pierde" para la colectividad.

\section{EL ESPACIO, LA ECONOMIA Y EL TIEMPO: FORMAS DE VIDA EN ISTÁN}

Istán está situado entre altas Sierras, atravesadas por el rio Verde cuyo nombre obedece al color de sus aguas. Escarpes cubiertos por una espesa y rica flora conforman un valle aislado, paraíso recóndito, lleno de lugares míticos: Plaza de Armas en Sierra Real, el Cerro de los Castillejos, el Fuerte de Arboto, que sirvió a Omar Ben Hafsun para la conquista de Andalucía. Estos topónimos nos remiten a un pasado beligerante, de "hondas raíces moriscas", que han marcado la configuración espacial del pueblo y han dejado rastro en los nombres de sus habitantes. En efecto, durante la obligada conversión religiosa, los moriscos adoptaron los nombres de los frutos de la tierra, y diéronse en llamar: Trigo, Granados, Naranjo, apellidos que aún perduran ${ }^{8}$.

El carácter serrano del entorno, su marcada aislamiento, la carencia de tierras apropiadas para el cultivo, dieron lugar a una economía basada en los productos del esparto, de los árboles y la cría de ganado. Econo-

\footnotetext{
? Para profundizar en las técnicas del saber narrativo, es necesaria la consulta de LiotaRd, J. F., La condición postmoderna. Informe sobre el saber. Madrid, Cátedra, 1984. Aquí el autor hace un estudio comparado de la cultura narrativa y la cultura científica.

${ }^{8}$ La huella del rasado morisco de Istán registrada en los libros de DE MARmol CarVAJAL, Luis, Historia de la rebelión y castigo de los moriscos del reyno de Granada. Madrid, Imprenta Sancha, 1797; de HuRTADo DE MENDOZA, Diego, Guerra de Granada. Lucha por el Rey Don Felipe II contra los moriscos de aquel reino y sus rebeldes. Valencia, 1830, y de Caro Baroja, Julio, Los moriscos del reino de Granada. Madrid, Istmo, 1976.
} 
mía que traza la concepción del tiempo y estructura la vida de los habitantes, hasta que se produce el impacto del turismo en la comarca. Antes de este suceso la vida diaria se regulaba de la siguiente manera: los hombres salian al campo a una hora temprana. Para ellos, estaban reservados los mejores alimentos: tocino, verdura, pan, fruta. El resto de la familia almorzaba una sopa, mientras que la comida fuerte - potajes, pucheros - se hacía de noche, cuando los hombres volvían a casa, con objeto de recuperar fuerzas. "Durante la noche se velaba para hacer pleita", actividad en la que participaban todos los miembros de la familia. Consistía en la elaboración artesanal de cestas, ceretes de higos, canastas, etc., hechas con esparto. Los productos obtenidos se intercambiaban en la tienda por comestibles. Así se solventaba el hambre, y las familias salían adelante. Hacer pleita era una labor realizada mayormente por mujeres y niños. No se consideraba trabajo, sino una prolongación de las faenas del hogar.

La división del tiempo, estaba en función de las labores cotidianas determinadas por esta forma particular de supervivencia. «El tiempo lento fluía" en esta comunidad que trabajaba de noche y de día. Donde sólo se interrumpía la actividad en días muy señalados del calendario, para festejar el inicio de la primavera - las carretoliendas, carnavales - y rendir culto a los muertos - día de difuntos- El ritmo temporal era marcado desde el interior de la colectividad sin atender a los acontecimientos oficiales. Para diferenciar épocas se decía: "en tiempos de Juan Lomeña", se recurría a personajes de la comunidad para nombrar períodos sucesivos de tiempo pasado. Sólo un hecho histórico marcaría el rumbo de este "tiempo interior»: la Guerra Civil. Las mujeres emplean este suceso como una fecha de referencia, sin duda por el impacto que causó en la experiencia colectiva e individual.

Una economía serrana, pobre, hará que Istán posea un régimen social específico. A diferencia de otros pueblos de Andalucia donde la propiedad de la tierra -el latifundio- imponía las jerarquías. En Istán, se tenían en cuenta otros "valores" para establecer las diferencias sociales. Efectivamente, la posesión y herencia de cargos en el Ayuntamiento, y el hecho de tener estudios de saber leer y escribir, permitió a la familia Moreno perpetuarse doscientos años en la Alcaldía. Plataforma idonea para llevar a cabo sus prácticas usureras haciendo trampa en los papeles. Esto consistia en poner una fecha de caducidad en los contratos que no era la estipulada de palabra con la gente analfabeta - mayoria en el pueblo-. El resultado era el vencimiento de los plazos y la rápida acumulación de bienes ajenos. 
La distribución social del conocimiento establecía la jerarquía social, que se plasmaba en el espacio del lugar de forma acentuada: En la Plaza, centro del pueblo, vivían los ricos; a las afueras, en El Peñón, sobrevivian los pobres. Nadie podia concebir un casamiento entre familias de diferente escala social. Por otra parte, nunca sucedió.

\section{LA FORMACIÓN DEL PENSAMIENTO FEMENINO}

\section{Aprender a ser mujer. La socialización en la esfera privada}

"La palabra humana está montada sobre los paisajes". El medio habitado se nombra constantemente. $Y$ en Istán el lenguaje tiene relieve de Sierra y hace pleita. Esto quiere decir que las condiciones geográficas y económicas de un lugar determinan el lenguaje, de la misma manera que a las restantes facetas humanas. Según el antropólogo Carmelo Lisón Tolosana: "La lengua es un modo de vida" ${ }^{\text {. }}$.

Pero no sólo el espacio geográfico condiciona la vida de los hombres, también a menor escala existen determinaciones importantes. Este es el caso de la utilización histórica del espacio privado como ámbito reservado para la mujer. Aqui ha desarrollado tradicionalmente todas sus actividades, éste ha sido su reino. $Y$ es en la esfera privada donde distintas generaciones femeninas se han ido legando ideas, formas de comportamiento, hábitos, actitudes que cristalizaban en la reproducción del rol, heredado de madres a hijas.

"Es en el hogar donde las mujeres aprendian a ser mujeres". La formación del pensamiento femenino estaba determinado por el peso de la realización cotidiana. En la esfera privada se transmitía la cultura femenina a través de la palabra, utilizando los cauces de la cultura narrativa: canciones, refranes, cuentos, el relato de la tradiciones.

Prueba del peso del hogar en la formación del pensamiento y la conducta de la mujer es "la determinación del habla». Ciertamente el aislamiento en el espacio privado del género femenino ha condicionado hasta su pronunciación Diversos tratados de Dialectología y Sociolingüís-

${ }^{9}$ Lison Tolosana, Carmelo, Antropología social y hermenéutica. Méjico, FCE, 1983. 
tica señalan la pervivencia de rasgos arcaizantes en el habla femenina frente a la masculina, más evolucionada, de una misma comunidad -el conservadurismo se constata por el grado de apertura de las vocales, entre otros factores-.

Sin duda alguna la relación de los géneros con las distintas esferas: privada y pública, ha dejado huella en sus formas de hablar. Mientras que el hombre tiene más posibilidades de ser influenciado por otros factores, al frecuentar la esfera pública, la mujer sujeta a un ámbito restringido, tiene más dificultades para adoptar los cambios e integrarse en la dinámica de la evolución de la lengua. Además, esto significa, que las mujeres se relacionaban principalmente con mujeres. Entre ellas se transmitieron oralmente las costumbres, las ideas, su cultura. Por lo tanto no es de extrañar que el género femenino, en lugares concretos, tenga un habla característica ${ }^{10}$.

En Istán, las relaciones femeninas se circunscribian dentro del género, hasta el noviazgo, incluso después del matrimonio, ya que el marido y los hijos se pasaban el día trabajando en el campo. "Todo ello selló la formación del pensamiento de la mujer, sometida a unos procesos de socialización donde la interiorización de las acciones, las pautas de comportamiento, el mimetismo, la imitación y la identificación con otras mujeres la llevaban a reproducir su rol» ${ }^{11}$.

\section{Francisca Ruiz Ponce o la Socialización escolar femenina en Istán durante el franquismo}

Con la introducción de la escuela en Istán, la socialización de la niñez pasa a ser compartida por la familia y la escuela. Aunque es esta última institución la que irá acaparando la mayoría de las funciones de socialización, debido a las ocupaciones de la familia para la supervivencia. En el pueblo son las niñas quienen reciben una mayor educación

${ }^{10}$ Alvar, M., El español hablado en Tenerife. Madrid, Consejo Superior de Investigaciones Cientificas, 1959.

"El concepto de pensamiento en el que nos hemos basado para realizar estas apreciaciones es el elaborado por Jean Piaget, que señala como: "el lenguaje tiene tres consecuencias esenciales para el desarrollo mental: un intercambio posible entre individuos, es decir, el inicio de la socialización de la acción, una interiorización de la palabra, es decir, la aparición del pensamiento propiamente dicho, que tiene como soportes el lenguaje interior y el sistema de los signos; y por último, y sobre todo, una interiorización de la acción". Plaget, J., Seis estudios de Psicología. Barcelona, Planeta-Agostini, 1985. 
escolar, ya que los niños tenían que ocuparse del ganado o trabajaban en el campo. Este hecho repercutiria en el nivel de instrucción de las mujeres, que en este caso es mucho más alto que el de los hombres, según un estudio elaborado sobre el censo de población para la creación de una Escuela de Adultos en el lugar.

Efectivamente, las mujeres de Istán, debido a las circunstancias históricas de su comunidad, tienen en general una buena dicción, se expresan con facilidad, y utilizan construcciones lingüísticas complejas pertenecientes a un código lingüístico elaborado. No en vano, algunas de ellas, accedieron al bachillerato y no pudieron seguir estudios superiores por el aislamiento del pueblo. Lo cual viene a demostrar una vez más, que son las condiciones culturales las que determinan el desarrollo de la inteligencia en el ser humano, sin depender de los géneros. Como nos indica la muestra de la Escuela de Adultos, refiriéndose a sus experiencias educativas: "el hombre desarrolla más su capacidad de percepción espacial debido a su trabajo, mientras que la mujer desarrolla más la capacidad del lenguaje ${ }^{12}$.

El desarrollo del pensamiento reflexivo en las mujeres de Istán tiene su expresión en la existencia de una erudita local en vez de un erudito, y de una Alcaldesa. Posiblemente este factor también contribuiría a que las mujeres profanasen los espacios masculinos por excelencia: bares, tabernas. A finales de los años cincuenta se las podía ver conversando, tomando café o echando una partida de cartas en las tascas; al igual que hoy. Otra ruptura, entre los espacios masculinos y femeninos, era llevada a cabo en los años sesenta, cuando un grupo de mujeres jugaba al balombolea en la plaza del pueblo. Las mujeres constituyen en istán una importante fuerza dinamizadora de cualquier acto colectivo.

La escuela, el nuevo ámbito de socialización, tuvo que ver en la adopción por parte de estas mujeres de actitudes que rompian moldes. Aunque también en la escuela aprendieron "la moral de la sumisión". Pues esta institución, con su progresiva actividad socializadora, imprimía un determinado carácter a la infancia. Transformaba las mentalidades, inculcando una serie de hábitos y de ideas en los niños, que facilitaban la asimilación de la ideología franquista y preparaba el terreno para admitir sin quebrantos los cambios económicos producidos en los años 60 . «En Istán, fue una maestra: Francisca Ruiz Ponce, la que moldeó durante años el pensamiento de distintas generaciones de mujeres". En el

12. Entrevista a P. G. R, 26 de enero de 1988. 
pueblo se la consideraba una institución, y efectivamente lo era. Gozaba de una enorme autoridad, infundia temor y respeto. Ella introdujo nuevas pautas de comportamiento en el lugar, correspondientes a las prácticas capitalistas y su culto a la productividad. A esto se añade, su contribución a la legitimación del franquismo y de la moralidad puritana a través de sus enseñanzas.

Francisca Ruiz Ponce dejó una profunda huella en la memoria colectiva de Istán. Su figura es una muestra del poder absoluto que ejercían los maestros en el ámbito rural durante el franquismo. Ellos cumplieron el papel de introductores, reproductores y legitimadores de la ideología franquista. La respuesta de las comunidades rurales - con una rica cultura popular- a la implantación de otra forma cultural, Institucionalizada y artificial, fue la de completa sumisión. Hay que tener en cuenta que la ideologia colonizadora era de los vencedores de una Guerra Civil ${ }^{13}$. En el fondo, se producia otro fenómeno, la minusvaloración de la cultura autóctona, de la cultura narrrativa, frente al saber oficial, escrito en libros y enseñado por personas con estudios, lo que estaba totalmente mitificado. Prueba de ello es "la sumisión a la autoridad del maestro y la veneración por la "cultura" adquirida en la escuela". En Istán, por ejemplo, a doña Paquita se le hacian toda clase de regalos. Uno de los testimonios nos indica lo siguiente: “... Mi padre cuando sembraba y cogia los ajos, hacía una ristra para doña Paquita, y las papas para doña Paquita, y ella tenía cosas de sobra porque todo el mundo le regalaba al principio de la cosecha lo mejor" ${ }^{14}$. Cuando la maestra paseaba por la calle, todo el mundo se asomaba a verla, corriéndose la voz: "Ahí viene doña Paquita". Las niñas temían que sus padres se enterasen de los castigos que les imponía, porque sus padres las castigaban más.

Francisca Ruiz Ponce llegó a Istán en 1934, su autoridad, era indiscutible en este pueblo aislado de la Serranía. Así que aqui se quedó, gozando de los privilegios otorgados por el magisterio ante gente tan modesta. Simpatizante de la Falange y de los ideales de José Antonio, entró a formar parte de la Sección Femenina durante la posguerra. «Ella propagaría los principios falangistas y del nacional-catolicismo a través de una enseñanza, con unas claves importantes, la Historia Sagrada y la construcción de un nuevo pasado del que se borran las huellas de la República». Esto era reforzado por actos simbólicos como la lectura del

13 TUÑon de LARA, M. (Dir): España bajo la Dictadura Franquista (1939-1975). Colección de Historia de España, tomo X, Barcelona, Ed. Labor, 1980.

${ }^{14}$ Entrevista a C.U.O., 26 de enero de 1988. 
testamento de José Antonio, hecho recordado especialmente por sus alumnas. De una de ellas, es este relato:

"El acto del cara al sol de la Cruz de los Caidos que eso no se me olvidará jamás... Eso era una cosa pintoresca, curiosa... Me acuerdo: la luz de la calle de noche que era apenas una lucecilla así, todas de noche en la Cruz de los Caídos con el baberito puesto. Ella con su camisa azul toda llena de medallas, leyéndonos el testamento de José Antonio que yo no sé si tenía diez o doce folios. Y Fernando, el aguacil, con un candil así. Todas alli firmes, como te movieras, sabías que al día siguiente no te perdonaba. Y a la hora de cantar el cara al sol como estaba pendiente de quien no se sabía la letra... Al dia siguiente teniamos que repetirlo treinta veces por escrito. Al final: ¡Arriba España!» ${ }^{15}$.

«En los método de enseñanza utilizados por la maestra tenía un gran peso la tradición oral y sus recursos". Esta emplea la moralejas, las canciones, las parábolas, "para adherir más fácilmente una realidad artificial» - en tanto que no tenía nada que ver con el entorno espacial, histórico y cultural del pueblo- a las conciencias de sus alumnas. Doña Paquita, definida por sus antiguas discípulas como una "maestra "de la calle y la escuela"", ejercía un control riguroso sobre la vida de las niñas en todos los aspectos, hasta el punto de cambiar las pautas de comportamiento femenino, adaptándolas a los hábitos de las sociedades capitalistas. Introdujo nuevos hábitos de higiene con revisión diaria del aseo, en un lugar donde no había servicios ni baños que facilitaran la limpieza frecuente. Las decía a las niñas como tenían que dormir: "había que quitarse toda, toda la ropa, y dormir con el camisón solamente...", y como cocinar. La leche, por ejemplo, había que hervirla tres veces; dice las mujeres que recuerdan todavía esta idea cada vez que realizan este acto. Les indicaba como tenian que hablar, como debía moverse una señorita. Cosas que han constituido recuerdos imborrables en el pensamiento de sus alumnas.

Doña Paquita imbuyó el concepto de tiempo productivo y el espíritu competitivo a sus discipulas a través de la rigidez de horarios, de los exámenes, de los premios y los castigos. Según la nota, se ocupaba un lugar en la clase, y se ganaba un libro al finalizar el curso. Incluso llegó a cambiar una costumbre de arraigada tradición en las culturas agrarias, las niñas, reconocidas por el mote de su familia, tuvieron que llamarse

${ }^{15}$ Entrevista a C.U.O., 27 de enero de 1988. 
obligatoriamente por sus nombres propios, con lo cual se separaba, se diferenciaba al individio del grupo. La consecuencia era la creación de un sujeto autónomo frente a la colectividad. Esta maestra preparaba a las alumnas para que fuesen elementos productivos y de cara a una nueva realidad donde se rindiera culto al productivismo.

Por otra parte, "les inculcaba una moralidad cuyas claves eran la sumisión, la obediencia, la abnegación y la humildad". Recurría a las parábolas, a las canciones para imprimir estos valores en el pensamiento femenino. Entre estas coplas, destacaba «la humilde violeta», donde se ponia de relieve la virtud de la modestia. La letra era la siguiente:

“Junto al sendero noté un perfume,
busqué la causa y hallé una flor.
Ella sola se marchitaba
entre las hojas sin pretensión.
¡Ay!, ¡Ay! que aroma tan fino,
por él, por él, se la descubrió.
Era una humilde, suave violeta,
que un bello dia alli nació.
Ella daba todo su aroma,
en alabanza del creador.
¡Ay! ¡Ay! que aroma tan fino,
por él, por él, se la descubrió"

Después de cada canción daba normas de comportamiento, señalaba como había que ser, marcaba cuáles eran los buenos pensamientos. En este caso se rendía culto a la insignificancia en contra del autorreconocimiento y del amor propio. Esta moral estaba reforzada por los principios religiosos católicos, que debian cumplir a rajatabla -ir a misa los domingos, ponerse el velo, confesar, etc...- si no querian ser castigadas.

Otra de las bases de la educación impartida por Doña Paquita a sus alumnas, junto a las matemáticas y la lengua, era el rechazo de los hombres. Les infundía temor hacia los hombres, y terror a la sexualidad. Su animadversión por las relaciones entre los distintos sexos se manifestaba en los castigos ejemplares impuestos a las niñas que hubiesen hablado con un muchacho o hubieran bailado con alguno. Mantenía una vigilancia intensiva sobre este aspecto, a través de sus amistades. Se

${ }^{16}$ La autora de la canción, según nos indican varios testimonios, era Francisca Ruiz Ponce, quien componía todas las letras de las coplas que enseñaba a sus alumnas. 
enteraba de todo lo que sucedia, para después, en la clase, castigar a quien transgredía la norma. No queria que las chicas se echasen pronto novio. $Y$ las exhortaba a que desarrollaran su personalidad, estudiasen, y dejasen de pensar en el matrimonio como la única salida para la mujer. No había que temer ni a la soltería, ni al trabajo. Una de las principales máximas que inculcaba a sus alumnas era: "Nunca ser maniqui de un hombre». Reivindicaba una identidad femenina independiente pero a costa de la represión, el temor y el desprecio al género masculino.

Esta ideologia conformó el pensamiento de varias generaciones de mujeres. Fue imbuida gracias a unos medios: la disciplina, los castigos y la creación del complejo de culpabilidad - todo era pecado-. El período de socialización primario facilitó la asimilación de este discurso por parte de las alumnas. Ya que en esta etapa se produce una identificación, con una gran carga emocional, del niño con el maestro: así que éste puede imprimir con facilidad determinadas ideas en sus discipulos ${ }^{17}$. De esta manera se entiende que las alumnas asumieran la represión, la justificaran, incluso reprodujesen el rol que Doña Paquita les había fijado en la mente. Por lo tanto, se produce el fenómeno comprensible, de una gran admiración por la figura de la maestra: "a la que se le debe todo", se la recuerda constantemente, y se le habla a los hijos de sus enseñanzas.

Ciertamente, Doña Paquita trabajó mucho para instruir a estas mujeres. El número de niñas en clase rozaba la centena, y eran de todas las edades. Se preocupó de preparar a las más adelantadas para hacer el Bachillerato, incluso les acompañaba a Málaga cuando se realizaban los exámenes. "Pero las alumnas de los últimos años -la generación del setenta-, aún reconociendo su buena voluntad, hablan de su excesiva disciplina, de los prejuicios causados por la sensación constante de culpabilidad, del temor infundido como algo negativo para una persona. $Y$ admiten que estos sentimientos han sellado su vida, su pensamiento y su forma de comportarse. De alguna manera han asumido la moralidad inculcada por su maestra".

La cultura oficial propugnada desde la escuela, era aceptada masivamente. Si había alguna oposición se manifestaba a través de la rebeldia infantil dentro de clase. Precisamente, una de sus alumnas, Inés Ayllón, prefería estar con los viejos y aprender de ellos antes que sentarse en un pupitre. Ella, no se sometía a las reglas del saber impuesto, y su forma de protestar era poniéndole ratones a la maestra en su silla

17 Ibidem, (nota 1). 
o acusarla de favoritismo. Su afición por los viejos hacía que la gente le dijera: "AAy! Inesilla si parece que tienes un viejo en la barriga". Su actitud, no era tan extraña, ya que los viejos se encargaban de legar las costumbres a los miembros más jóvenes de la comunidad en las sociedades agrarias precapitalistas ${ }^{18}$. $Y$ esta forma de saber aún no había declinado en Istán. La resistencia de Inés, era interpretada por sus compañeras y la maestra como torpeza, por eso siempre estaba en la última fila. Esta mujer es hoy maestra y Alcaldesa de Istán.

\section{CONCLUSIONES}

"A pesar de la moral recibida, estas mujeres rompieron moldes en la comunidad que habitaban". Liberaron espacios estrictamente masculinos para ser utilizados por ambos géneros. Esto era impensable en el ámbito rural andaluz durante el Franquismo. Ellas hubieran querido continuar sus estudios pero lo impedía el aislamiento del pueblo, la escasez monetaria y la mentalidad conservadora de sus padres. El matrimonio, seguia siendo la única salida para las mujeres de Istán, aunque fuesen a la escuela y aprendieran el valor de la independencia femenina.

La consolidación de la escuela en el medio rural, señalaba la imposición definitiva de los valores urbanos en el seno de la sociedad agraria, que se convertiría con el paso del tiempo en un apéndice de la ciudad ${ }^{19}$. Este hecho tenia además otras connotaciones: la pérdida por parte de la familia de su función socializadora y como consecuencia el debilitamiento de la cultura narrativa. Y por ende el aumento del poder y del control del estado en las comunidades rurales a través de su brazo ideológico: la escuela; la máquina idónea para propagar los principios capitalistas e imponer los dictámenes oficiales, en este caso los del Franquismo.

A todos estos cambios contribuyó Doña Paquita con sus enseñanzas. Utilizó los cauces de la transmisión oral para sellar el pensamiento

18 Gonzalo Anes señala como en las sociedades agrarias precapitalistas: "Los niños aprendian en los hogares de las casas cuentos, consejos, romances, tradiciones, costumbres, de labios de sus abuelos, con achaques que le impedian trabajar en el campo, pero sí cuidar de los pucheros y de los niños, mientras sus padres araban, escardaban, segaban las mieses o atendian a sus ganados. Alli se producía la "soldadura generacional", que permitía a los ancianos ejercer su influencia y transmitir las tradiciones, asegurando su conservación". En ANES, Gonzalo, (Dir), Agricultura. La economía española al final del Antiguo Régimen. Madrid, Alianza Editorial, 1982.

19 Lefebure: La revolución urbana. Madrid, Alianza, 1983. 
de las mujeres de Istán. Todas ellas recuerdan perfectamente las canciones de su maestra. Cuando las cantaron a coro, daba la impresión de que el tiempo no había pasado. Así de profunda era la huella en sus memorias, de las enseñanzas recibidas. Sin duda alguna, la maestra formó la identidad de sus alumnas. 